\title{
Fitossociologia do banco de sementes de plantas daninhas em campo agrícola e vegetação de cerrado
}

O conhecimento do banco de sementes e índices fitossociológicos de plantas daninhas pode antecipar informaç̃̃es sobre os efeitos das práticas de manejo agronômico e fornecer subsídios para recomposição da cobertura vegetal. Objetivou-se realizar a caracterização fitossociológica da comunidade infestante em campo agrícola e vegetação densa de cerrado, através da amostragem do banco de sementes. O experimento foi conduzido em vasos plásticos de 6,38 dm3, sob $25 \%$ de sombreamento. Para isso, fez-se a amostragem de 50 pontos em campo agrícola experimental e área com vegetação densa de cerrado. Realizou-se a coleta em distâncias regulares de $10 \times 10 \mathrm{~m}$ e profundidade de 0 a $20 \mathrm{~cm}$. As plantas foram identificadas com auxílio de literatura especializada e quantificadas aos 20 , $40,60,80,100$ e 120 dias. Estimou-se a densidade, frequência e abundância absolutas e relativas, índice de valor de importância relativa, índice de dispersão e índice de similaridade de Sorensen. A família Poaceae é a mais importante nas duas áreas amostradas, ao passo que entre as espécies Mollugo verticillata L. $(69,82 \%)$ na área experimental e Richardia scabra L. $(55,12 \%)$ na vegetação de cerrado. As duas áreas apresentam alto índice de similaridade $(73,33 \%)$, com 11 espécies em comum. A predominância de espécies herbáceas, colonizadoras e elevada similaridade com o campo agrícola experimental, indica a antropização da área de cerrado e reflete sobre a necessidade de práticas conservacionistas para sua restauração. O índice de dispersão indicou distribuição agregada (reboleira) para maioria das espécies, o que pode permitir estratégias eficientes no controle da comunidade infestante, focalizados nos pontos de maior probabilidade de infestação, especialmente no campo agrícola experimental.

\section{Phytosociology of the seed bank of weeds in agricultural field and vegetation of cerrado}

\begin{abstract}
The knowledge of the seed bank and phytosociological indexes of weeds can anticipate information about the effects of agronomic management practices and provide subsidies for recomposition of vegetation cover. The aim was to carry out the phytosociological characterization of the weed community in agricultural fields and dense cerrado vegetation, through the sampling of the seed bank. The experiment was carried out in $6.38 \mathrm{dm} 3$ plastic pots, under $25 \%$ shading. For this, 50 points were sampled in an experimental agricultural field and an area with dense cerrado vegetation. The collection was carried out at regular distances of 10 $x 10 \mathrm{~m}$ and depth from 0 to $20 \mathrm{~cm}$. The plants were identified with the help of specialized literature and quantified at 20, 40, 60, 80, 100 and 120 days. The absolute and relative density, frequency and abundance, relative importance value index, dispersion index and Sorensen similarity index were estimated. The Poaceae family is the most important in the two sampled areas, whereas among the species Mollugo verticillata L. (69.82\%) in the experimental area and Richardia scabra L. $(55.12 \%)$ in the cerrado vegetation. The two areas have a high similarity index $(73.33 \%)$, with 11 species in common. The predominance of herbaceous species, colonizers and high similarity with the experimental agricultural field, indicates the anthropization of the cerrado area and reflects on the need for conservationist practices for its restoration. The dispersion index indicated aggregate distribution for most species, which can allow efficient strategies in the control of the weed community, focused on the most likely points of infestation, especially in the experimental agricultural field.
\end{abstract}

Keywords: Anthropization; Weeding Community; Conservation; Dispersal; Flora.

Topic: Desenvolvimento, Sustentabilidade e Meio Ambiente

Reviewed anonymously in the process of blind peer.
Received: 06/05/2020

Approved: 04/06/2020
Klayton Antonio do Lago Lopes (iD) Universidade Federal do Maranhão, Brasil http://lattes.cnpq.br/2061482776415137 http://orcid.org/0000-0001-8645-4174 klaytonlopes2011@gmail.com

Marcelo de Sousa da Silva (iD) Universidade Federal do Maranhão, Brasil http://lattes.cnpq.br/5929903987543113 http://orcid.org/0000-0002-6074-8761 marcelosousamj@hotmail.com

Leandro dos Santos Costa (iD) Universidade Federal do Maranhão, Brasil http://lattes.cnpq.br/9896743847859067 http://orcid.org/0000-0003-1117-1115 santleandrocosta@gmail.com

\section{Ana Karla da Silva Oliveira (iD) \\ Universidade Federal do Maranhão, Brasi http://lattes.cnpq.br/9706421371345666 http://orcid.org/0000-0001-9596-1784 karlinha_oliveira95@hotmail.com \\ Eduardo Arouche da Silva (iD \\ Universidade de São Paulo, Brasil http://lattes.cnpq.br/0128682504052393 http://orcid.org/0000-0001-6081-0011 eduardoarouche@usp.br \\ Edmilson Igor Bernardo Almeida (iD) Universidade Federal do Maranhão, Brasi http://lattes.cnpq.br/4485991332506597 http://orcid.org/0000-0003-2051-7085} edmilson i@hotmail.com

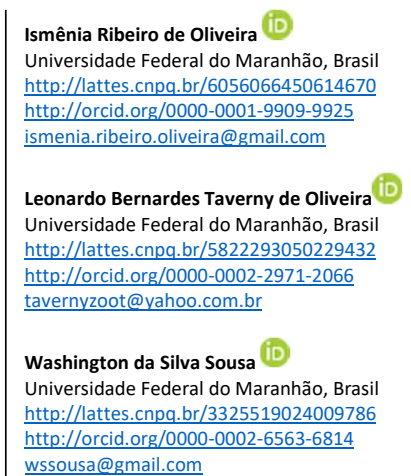

José Roberto Brito Freitas (iD) Universidade Federal do Maranhão, Brasil http://lattes.cnpq.br/5427491615270649 http://orcid.org/0000-0003-0513-4211 joserobertobritofreitas@yahoo.com.br

\section{Referencing this:}

LOPES, K. A. L.; SILVA, M. S.; COSTA, L. S.; OLIVEIRA, A. K. S.; SILVA, E. A.; ALMEIDA, E. I. B.; OLIVEIRA, I. R.; OLIVEIRA, L. B. T.; SOUSA, W. S.; FREITAS, J. R. B.. Fitossociologia do banco de sementes de plantas daninhas em campo agrícola e vegetação de cerrado. Revista IberoAmericana de Ciências Ambientais, v.11, n.4, p.362-370, 2020. DOI: http://doi.org/10.6008/CBPC2179-6858.2020.004.0029 


\section{INTRODUÇÃO}

O cerrado apresenta elevada biodiversidade e riqueza de espécies, porém geralmente ameaçadas de extinção pela intensa antropização. Comparado à Amazônia apresenta desvantagem do ponto de vista de proteção legal em terras privadas, pois a reserva legal engloba apenas $20 \%$, tornando-o muito vulnerável às ações antrópicas (CALDEIRA et al., 2020).

O conhecimento sobre a composição e densidade do banco de sementes apresenta-se como uma estratégia importante para o entendimento e manutenção da dinâmica ecológica de áreas naturais, o que auxilia na conservação de espécies com relevante interesse ecológico, além de participar da regeneração natural de ambientes antropizados (LEAL FILHO et al., 2013). Por sua vez, em campos agrícolas, o banco de sementes é geralmente a principal fonte de plantas daninhas, as quais podem ocasionar quedas médias de 30 a 40\% na produtividade de culturas agrícolas (MESQUITA et al., 2014; NORSWORTHY et al., 2012).

A variabilidade e densidade do povoamento de sementes de plantas daninhas no solo são resultantes do balanço entre entradas e saídas de novas sementes no sistema (AMIM et al., 2016). As entradas ocorrem via chuva de sementes, através de eficientes mecanismos de dispersão, e as saídas, por meio da germinação, deterioração, parasitismo, predação e transporte (MESQUITA et al., 2014).

As plantas daninhas são facilmente adaptadas a ambientes constantemente perturbados, principalmente devido a fatores ligados às sementes, tais como, elevada produção, eficiente dispersão, longevidade e especialmente dormência (SILVA et al., 2014), além de variar significativamente em resposta às características edafoclimáticas e as práticas agronômicas adotadas (SILVA et al., 2018), as quais podem propiciar o potencial regenerativo de várias espécies, mesmo na ausência de produção de sementes por longo período, tornando-se a principal dificuldade no controle de plantas daninhas (SILVA et al., 2014).

O conhecimento da dinâmica, densidade e diversidade das espécies daninhas, por meio de amostragens do banco de sementes do solo, permite a identificação e a quantificação da flora infestante, bem como a determinação da sua evolução. Um dos principais aspectos a ser considerado em levantamentos fitossociológicos são as tendências de variação da importância, de uma ou mais espécies. Certamente, estas variações podem estar relacionadas às práticas agrícolas adotadas, alterando a composição de uma determinada comunidade, particularmente na formação de um banco de dissemináculos no solo, que propicia sua presença continuada dentro do sistema de produção (SILVA et al., 2018).

Na determinação do grau de importância de uma determinada espécie, podem ser adotados índices fitossociológicos (LIMA et al., 2014). Esses índices se tornam uma ferramenta importante na comparação das espécies presentes na comunidade de plantas em uma área, em uma condição específica, tornando-se possível analisar variações populacionais, em função das práticas de manejo adotadas (CONCENÇO et al., 2013).

Esse conhecimento permite antecipar informações sobre os efeitos das práticas de manejo agronômico e os distúrbios naturalmente provocados, fornece subsídios para a elaboração de metodologia de recomposição da cobertura vegetal (COSTA et al., 2013), assim como orienta sobre a necessidade de 
controle, o qual deverá ser adequado aos diferentes sistemas de manejos da cultura (MESQUITA et al., 2014). Diante do exposto, objetivou-se realizar a caracterização fitossociológica da comunidade infestante em campo agrícola e vegetação de cerrado, através da amostragem do banco de sementes.

\section{MATERIAIS E MÉTODOS}

O experimento foi conduzido em ambiente telado ( $25 \%$ de sombreamento) entre os meses de janeiro e abril de 2019, no Centro de Ciências Agrárias e Ambientais (CCAA), Campus IV, Universidade Federal do Maranhão (UFMA), Chapadinha, Maranhão, Brasil, coordenadas 0344'28,7" S; 4318'46" W e 107 m de altitude. O clima nesta região é classificado por Köppen como Aw, quente e úmido. Apresentando precipitação média anual de 1.613 mm e temperatura média anual de 27,9ํC (PASSOS et al., 2016).

A amostragem foi realizada em duas áreas com características aparentemente distintas: campo agrícola experimental e vegetação densa de cerrado, ambas situadas no CCAA, UFMA. A primeira (Área 01) consistiu num campo agrícola experimental em pousio, com histórico de cultivos anuais, especialmente de soja e milho nos últimos 3 anos; a segunda (Área 02) representou uma vegetação densa de cerrado, situada no CCAA/UFMA e supostamente conservada.

Foram coletadas 25 amostras de solo em cada área, com distâncias regulares de $10 \times 10 \mathrm{~m}$. As amostras de solo foram retiradas com auxílio de enxada numa área circular correspondente a 0,05 $\mathrm{m}^{2}$, profundidade de $0,00-0,20 \mathrm{~m}$ de solo, e posteriormente acondicionadas em vasos plásticos de $6,38 \mathrm{dm}^{3}$, sob ambiente telado (25\% de sombreamento).

Os fluxos de emergências foram analisados aos 20, 40, 60, 80, 100 e 120 dias. Após cada fluxo de emergência, as plantas foram identificadas com o auxílio de literatura especializada (LORENZI, 2008), quantificadas e retiradas do vaso. Quando não foi possível a identificação na fase inicial da espécie, fez-se o transplantio para posterior cultivo e identificação. Aos 60 dias após a instalação do experimento, realizou-se revolvimento do solo para estimular novos fluxos de emergência, conforme recomendado por Monquero et al. (2008).

Para a caracterização da comunidade infestante estimou-se a frequência absoluta (1) e relativa (2) densidade absoluta (3) e relativa (4), abundância absoluta (5) e relativa (6), índice de valor de importância relativa (7) (MUELLER-DOMBOIS et al., 1974) e índice de dispersão, os quais foram calculados pelas seguintes fórmulas:

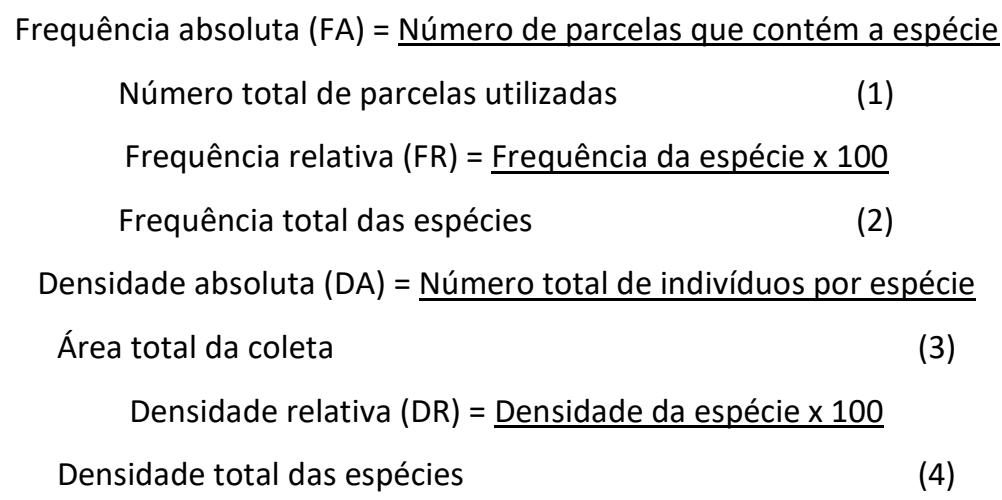


Abundância $(A B)=$ Número total de indivíduos por espécie

Número total de parcelas contendo a espécie

Abundância relativa $(A B R)=\underline{\text { Abundância da espécie } \times 100}$

Abundância total das espécies

(6)

Índice de Valor e Importância (IVI) = FR + DR + ABR

Índice de dispersão (ID) $=\sigma^{2} / \mu$

No qual " $\sigma$ " indicou a variância e " $\mu$ " se referiu a média (CARDINA et al., 1995; SHIRATSUCHI, 2005). Valores maiores que a unidade $(1,0)$ expressou distribuição agregada (SCHAFFRATH et al., 2007). O Índice de Similaridade de Sorensen (IS) foi estimado para analisar a similaridade das espécies encontradas no banco de sementes do solo nos dois ambientes de amostragem, calculado pela equação 9:

$$
\text { Índice de Similaridade de Soresen (IS) }=(2 \mathrm{a} / \mathrm{b}) \times 100
$$

No qual "a" consistiu no número de espécies comuns nas duas áreas amostradas e "b" se referiu ao número total de espécies nas duas áreas amostradas (FERREIRA et al., 2014; JAKELAITIS et al., 2014; LOUSADA et al., 2017)

\section{RESULTADOS E DISCUSSÃO}

Na área experimental foram identificadas 17 espécies de plantas daninhas, pertencentes a 13 famílias botânicas, totalizando 3.303 plântulas emergidas. Entre as famílias, destacaram-se a Poaceae com três espécies e a Asteraceae e Rubiaceae com duas espécies cada (Tabela 1).

Tabela 1: Número de espécies de plantas daninhas emergidas no banco de sementes no campo agrícola experimental e vegetação de cerrado.

\begin{tabular}{llll}
\hline Família & Nome científico & Campo Experimental & Cerrado \\
\hline Amaranthaceae & Alternanthera tenella Colla & 3 & 135 \\
Asteraceae & Emilia coccinea (Sims) G. Don & 78 & 0 \\
Commelinaceae & Jaegeria hirta (Lag.) Less. & 1 & 0 \\
Cyperaceae & Tradescantia fluminensis Vell. & 1 & 249 \\
Euphorbiaceae & Cyperus iria L. & 146 & 164 \\
Fabaceae-Mimosoideae & Dalechampia scandens L. & 0 & 10 \\
Limiaceae & Chamaesyce prostrata (Aiton) Small. & 60 & 54 \\
Malvaceae & Marsyosa hirsutissima Mart. & 8 & 0 \\
Molluginaceae & Sida rhombifolia L. & 7 & 0 \\
Plantaginaceae & Mollugo verticillata L. & 835 & 34 \\
& Scoparia ducis L. & 1057 & 0 \\
Poaceae & Coix lacryma-jobi L. & 298 & 7 \\
& Cenchrus echinatus L. & 18 & 31 \\
Rubiaceae & Eleusine indica (L.) Gaertn. & 157 & 21 \\
Solanaceae & Spermacoce capitata Ruiz \& Pav. & 409 & 226 \\
Turneraceae & Richardia scabra L. & 62 & 0 \\
\hline
\end{tabular}

Resultados semelhantes foram relatados por Caetano et al. (2018), ao realizar levantamento fitossociológico na cultura da soja em Luís Eduardo Magalhães (BA), os quais observaram maior representatividade para as famílias Poaceae e Asteraceae. Bandeira et al. (2018) também constataram as famílias Poaceae e Asteraceae como de maior abundância de espécies em cultivo de feijão-caupi na Bahia. 
Quanto ao número de plântulas emergidas no banco de sementes, as espécies mais representativas foram a Mollugo verticillata L. (1057), Sida rhombifolia L. (835) e Eleusine indica (L.) Gaertn. (409) (Tabela 1). Segundo Lorenzi (2008), o Mollugo verticillata L. é uma planta de ciclo curto, encontrada praticamente em todos os estados brasileiros, sendo mais frequente na região Nordeste, em áreas de jardins, pomares, hortas e lavouras anuais. Corrêa et al. (2015) também relataram uma elevada densidade desta espécie, entre 30 e 60 dias após a emergência de feijão-caupi, cultivado em São Luís/MA.

Na área de cerrado foram identificadas 13 espécies, pertencentes a 10 famílias botânicas, totalizando 1260 plântulas emergidas. Quanto às famílias com maior número de espécies destacaram-se as famílias Poaceae e Euphorbiaceae com três e duas espécies, respectivamente. Em consonância a estes resultados, Lau et al. (2014) ao estudarem a composição e densidade do banco de sementes em uma floresta de várzea em Belém/PA, também encontraram as famílias Poaceae e Euphorbiaceae como as mais representativas. De acordo com Figueiredo et al. (2014), a intensa incidência da família Poaceae está associada a indícios de perturbações antrópicas em florestas.

No que diz respeito ao número de plântulas emergidas no banco de sementes na área de cerrado, as espécies mais representativas foram a Richardia scabra L., Tradescantia fluminensis Vell. e Eleusine indica (L.) Gaertn. (Tabela 1). Com a emergência das plântulas, observaram-se 11 espécies em comum, apresentando índice de similaridade de 73,33\%. A similaridade entre as duas áreas amostradas enfatiza a possibilidade de impactos antrópicos, com consequente alteração da vegetação natural (cerrado), embora aparentemente apresentava-se como uma vegetação densa bem preservada. A espécie com maior intensidade na área experimental foi a Mollugo verticillata $\mathrm{L}$. com DA de 21.527,49 sementes $\mathrm{m}^{-2}$, FA de 92,00\% e IVI igual a 69,82\% (Tabela 2). De acordo com Caetano et al. (2018), isso demonstra que esta espécie possui uma alta influência dentro da comunidade estudada.

Tabela 2: Índices fitossociológicos das espécies de plantas daninhas emergidas no banco de sementes da área experimental.

\begin{tabular}{|c|c|c|c|c|c|c|c|c|}
\hline Nome científico & DA & FA & DR (\%) & FR (\%) & AB & ABR (\%) & IVI(\%) & ID \\
\hline \multicolumn{9}{|c|}{ Campo Experimental } \\
\hline Alternanthera tenella Colla & 61,10 & 4,00 & 0,09 & 0,41 & 3,00 & 1,85 & 2,35 & 3,00 \\
\hline Emilia coccinea (Sims) G. Don & 1588,59 & 80,00 & 2,36 & 8,30 & 3,90 & 2,40 & 13,06 & 4,68 \\
\hline Jaegeria hirta (Lag.) Less. & 20,37 & 4,00 & 0,03 & 0,41 & 1,00 & 0,62 & 1,06 & 1,00 \\
\hline Tradescantia fluminensis Vell. & 20,37 & 4,00 & 0,03 & 0,41 & 1,00 & 0,62 & 1,06 & 1,00 \\
\hline Cyperus iria L. & 2973,52 & 84,00 & 4,42 & 8,71 & 6,95 & 4,28 & 17,41 & 7,00 \\
\hline Chamaesyce prostrata (Aiton) Small. & 1222,00 & 84,00 & 1,82 & 8,71 & 2,86 & 1,76 & 12,29 & 1,84 \\
\hline Mimosa hirsutissima Mart. & 162,93 & 28,00 & 0,24 & 2,90 & 1,14 & 0,70 & 3,85 & 0,97 \\
\hline Coix lacryma-jobi L. & 366,60 & 28,00 & 0,54 & 2,90 & 2,57 & 1,58 & 5,03 & 3,07 \\
\hline Cenchrus echinatus L. & 3197,56 & 80,00 & 4,75 & 8,30 & 7,85 & 4,83 & 17,88 & 8,15 \\
\hline Eleusine indica (L.) Gaertn. & 8329,94 & 100,00 & 12,38 & 10,37 & 16,36 & 10,06 & 32,82 & 8,77 \\
\hline Marsypianthes chamaedrys (Vahl) Kuntze & 142,57 & 4,00 & 0,21 & 0,41 & 7,00 & 4,31 & 4,93 & 7,00 \\
\hline Sida rhombifolia L. & 17006,11 & 100,00 & 25,28 & 10,37 & 33,40 & 20,55 & 56,20 & 95,62 \\
\hline Mollugo verticillata $\mathrm{L}$. & 21527,49 & 92,00 & 32,00 & 9,54 & 45,96 & 28,27 & 69,82 & 45,22 \\
\hline Scoparia ducis L. & 6069,25 & 84,00 & 9,02 & 8,71 & 14,19 & 8,73 & 26,47 & 25,45 \\
\hline Richardia scabra L. & 1812,63 & 52,00 & 2,69 & 5,39 & 6,85 & 4,21 & 12,30 & 8,03 \\
\hline Spermacoce capitata Ruiz \& Pav. & 1262,73 & 48,00 & 1,88 & 4,98 & 5,17 & 3,18 & 10,03 & 3,90 \\
\hline Turnera subulata Sm. & 1507,13 & 88,00 & 2,24 & 9,13 & 3,36 & 2,07 & 13,44 & 2,86 \\
\hline
\end{tabular}

$\mathrm{DA}$ = densidade absoluta; $F A$ = frequência absoluta; $D R=$ densidade relativa; $F R$ = frequência relativa; $A B=$ abundância; $A B R=$ abundância relativa; IVI = índice de valor de importância; ID = índice de dispersão. 
Em contrapartida, Lima et al. (2016) observaram IVI médio de apenas 5,2\%, dos 28 aos 56 dias após a emergência do feijão-caupi em Vitória da Conquista/BA. Baixos IVI também foram observados nas culturas da mandioca (CARDOSO et al., 2013), pastagens (COSTA et al., 2013), arroz de sequeiro (SILVA et al., 2014) e capim Aruana (SILVA et al., 2018), os quais divergem dos resultados obtidos no presente estudo. O que pode estar relacionado ao nível de antropização do campo agrícola experimental, pois trata-se de um campo agrícola experimental submetido a intensa utilização de herbicidas para o controle químico de plantas daninhas.

Todas as espécies identificadas na área experimental, com exceção da Jaegeria hirta (Lag.) Less., Tradescantia fluminensis Vell. e Mimosa hirsutissima Mart., mostraram comportamento agregado (reboleira), com Índice de Dispersão (ID) maior que 1,0. A Sida rhombifolia L. apresentou o maior ID $(95,62)$, seguido do Mollugo verticillata L. $(45,22)$. Chiba et al. (2010) relataram que essa grande variabilidade dos dados é típica do levantamento de plantas daninhas, pois ao mesmo tempo em que são realizadas amostras com poucas ou nenhuma espécie, há pontos com elevado número delas.

Schaffrath et al. (2007) relataram que o padrão de agregação das plantas daninhas pode ser dependente do sistema de manejo do solo, culturas e espécies infestantes presentes. Segundo Ferreira et al. (2013), os fatores ambientais e a menor eficácia do manejo cultural também possibilitam o desenvolvimento e a dispersão de sementes em áreas cultivadas, promovendo maiores infestações de plantas invasoras nas reboleiras.

Portanto, a adoção estratégica de medidas preventivas ou de controle propriamente dito pode focalizar na supressão nos pontos de maior infestação. Em casos que seja crucial a utilização do controle químico, a utilização dos herbicidas pode ser empregada em taxa variável a esta dinâmica de infestação, com redução dos custos de produção e impactos ambientais negativos decorrentes do uso inapropriado de agrotóxicos.

Tabela 3: Índices fitossociológicos das espécies de plantas invasoras emergidas no banco de sementes do cerrado antropizado.

\begin{tabular}{|c|c|c|c|c|c|c|c|c|}
\hline Nome científico & DA & FA & DR (\%) & FR (\%) & AB & ABR (\%) & IVI (\%) & ID \\
\hline \multicolumn{9}{|l|}{ Cerrado } \\
\hline Alternanthera tenella Colla & 109,98 & 84,00 & 10,71 & 11,48 & 6,43 & 9,45 & 31,64 & 20,06 \\
\hline Tradescantia fluminensis Vell. & 202,85 & 80,00 & 19,76 & 10,93 & 12,45 & 18,31 & 49,00 & 23,20 \\
\hline Cyperus iria $\mathrm{L}$. & 133,60 & 100,00 & 13,02 & 13,66 & 6,56 & 9,65 & 36,33 & 5,53 \\
\hline Dalechampia scandens $\mathrm{L}$. & 8,15 & 20,00 & 0,79 & 2,73 & 2,00 & 2,94 & 6,47 & 2,50 \\
\hline Chamaesyce prostrata (Aiton) Small. & 43,99 & 52,00 & 4,29 & 7,10 & 4,15 & 6,11 & 17,50 & 3,11 \\
\hline Sida rhombifolia L. & 27,70 & 28,00 & 2,70 & 3,83 & 4,86 & 7,14 & 13,67 & 5,57 \\
\hline Scoparia ducis L. & 5,70 & 24,00 & 0,56 & 3,28 & 1,17 & 1,72 & 5,55 & 1,05 \\
\hline Coix lacryma-jobi L. & 25,25 & 40,00 & 2,46 & 5,46 & 3,10 & 4,56 & 12,48 & 5,46 \\
\hline Cenchrus echinatus L. & 17,11 & 32,00 & 1,67 & 4,37 & 2,63 & 3,86 & 9,90 & 4,33 \\
\hline Eleusine indica (L.) Gaertn. & 184,11 & 92,00 & 17,94 & 12,57 & 9,83 & 14,45 & 44,96 & 6,63 \\
\hline Richardia scabra L. & 244,40 & 100,00 & 23,81 & 13,66 & 12,00 & 17,65 & 55,12 & 16,05 \\
\hline Solanum grandiflorum Ruiz \& Pav. & 16,29 & 52,00 & 1,59 & 7,10 & 1,54 & 2,26 & 10,95 & 1,04 \\
\hline Turnera subulata $\mathrm{Sm}$. & 7,33 & 28,00 & 0,71 & 3,83 & 1,29 & 1,89 & 6,43 & 1,13 \\
\hline
\end{tabular}

$\mathrm{DA}$ = densidade absoluta; $\mathrm{FA}$ = frequência absoluta; $\mathrm{DR}=$ densidade relativa; $F \mathrm{R}$ = frequência relativa; $\mathrm{AB}=$ abundância; $A B R=$ abundância relativa; IVI = índice de valor de importância; ID = índice de dispersão.

O banco de dissemináculos da área de cerrado foi formado basicamente por espécies herbáceas de 
caráter colonizador, com baixa ocorrência de espécies arbustivas e/ou arbóreas, o que pode enfatizar antropização da vegetação nativa. Esses resultados foram similares aos encontrados por Machado et al. (2013), os quais recomendaram o uso de técnicas de reflorestamento com espécies nativas, visando acelerar a restauração desses ambientes perturbados ao longo dos anos. As espécies de maior índice de valor importância relativa, na área de cerrado antropizado, foram a Richardia scabra L. (55,12\%), Tradescantia fluminensis Vell. (49,00\%) e Eleusine indica (L.) Gaertn. (44,96\%), respectivamente (Tabela 3).

A presença de espécies diferentes das que comumente são encontradas no estrato superior caracteriza uma possível perturbação antrópica na área, que pode ser em consequência de sua adaptação a ambientes sombreados e úmidos (LAU et al., 2014). No presente estudo, a densidade de sementes/espécies obtida na área de cerrado foi inferior ao campo agrícola experimental, possivelmente decorrente da capacidade supressora da sua vegetação, embora este ambiente apresentasse caracteres de antropização no banco de sementes. Em consonância, Lopes et al. (2020) evidenciaram maior incidência de plantas daninhas, da borda para o centro da mata, associado ao sombreamento imposto pela vegetação de cerrado.

Todas as espécies do cerrado antropizado mostraram comportamento agregado, ou seja, distribuídas em manchas ou reboleiras, indicado pelo índice de dispersão maior que 1,0 (ID>1,0). As espécies Tradescantia fluminensis Vell., Alternanthera tenella Colla e Richardia scabra L. destacaram-se com valores de 23,20, 20,06 e 16,05, respectivamente. Schaffrath et al. (2007) sugere que a ocorrência de um foco inicial pode ter promovido a produção e disseminação das sementes ou outras formas de multiplicação. Esse foco inicial pode ter ocorrido principalmente nas bordas da área por ações antrópicas e/ou naturais.

Os resultados obtidos no presente estudo podem auxiliar na adoção de estratégias eficientes no manejo de plantas daninhas, particularmente na área experimental. Estes podem ser ajustados a ferramentas da agricultura de precisão, em termos de posicionamento de defensivos agrícolas e, portanto, extrapolados metodologicamente para lavouras comerciais. Ao passo que em reservas legais ou vegetações densas, principalmente do bioma cerrado, podem contribuir para o conhecimento da antropização e dessa forma, propiciar alternativas para sua restauração com espécies nativas.

\section{CONCLUSÕES}

A família Poaceae é a mais importante nas duas áreas amostradas, ao passo que entre as espécies Mollugo verticillata L. $(69,82 \%)$ na área experimental e Richardia scabra L. $(55,12 \%)$ na vegetação de cerrado. As duas áreas apresentam alto índice de similaridade (73,33\%), com 11 espécies em comum. A predominância de espécies herbáceas, colonizadoras e elevada similaridade com o campo agrícola experimental, indica a antropização da área de cerrado e reflete sobre a necessidade de práticas conservacionistas para sua restauração. $O$ índice de dispersão indicou distribuição agregada (reboleira) para maioria das espécies, o que pode permitir estratégias eficientes no controle da comunidade infestante, focalizados nos pontos de maior probabilidade de infestação, especialmente no campo agrícola experimental. 


\section{REFERÊNCIAS}

AMIM, R. T.; FREITAS, S. P.; FREITAS, I. L. J.; SCARSO, M. F.. Banco de sementes do solo após aplicação de herbicidas pré-emergentes durante quatro safras de cana-de-açúcar. Pesquisa Agropecuária Brasileira, Brasília, v.51, n.10, p.1710-1719, 2016. DOI: https://doi.org/10.1590/s0100$\underline{204 \times 2016001000002}$

BANDEIRA, A. S.; LIMA, R. S.; TEIXEIRA, E. C.; NUNES, R. T. C.; NOVAIS, V. R.; SOUZA, U. O; PÚBLIO JUNIOR, E.. Levantamento fitossociológico de plantas daninhas na cultura do feijão-caupi. Cultura Agronômica, Ilha Solteira, v.27, n.2, p.327-340, 2018.

CAETANO, A. P. O.; NUNES, R. T. C.; RAMPAZZO, M. C.; SILVA, G. L.; SOARES, M. R. S.; SÃO JOSÉ, A. R.; MOREIRA, E. S.. Levantamento fitossociológico na cultura da soja em Luís Eduardo Magalhães/BA. Scientia Agraria Paranaensis, Marechal Cândido Rondon, v.17, n.3, p.359-367, 2018.

CALDEIRA, C.; PARRÉ, J. L.. Diversificação agropecuária e desenvolvimento rural no bioma Cerrado. Revista Americana de Empreendedorismo e Inovação American Journal of Entrepreneurship and Innovation, Paranaguá, v.2, n.1, p.344-359, 2020.

CARDINA, J.; SPARROW, D. H.; MCCOY, E. L.. Analysis of spatial distribution of common lambsquarters (Chenopodium album) in no-till soybean (Glycine max). Weed Science, Cambridge, v.43, n.2, p.258-268, 1995.

CARDOSO, A. D.; VIANA, A. E. S.; BARBOSA, R. P.; TEIXEIRA, P. R. G.; CARDOSO JÚNIOR, N. S.; FOGAÇA, J. J. N. L.. Levantamento fitossociológico de plantas daninhas na cultura da mandioca em Vitória da Conquista/Bahia. Bioscience Journal, Uberlândia, v.29, n.5, p.1130-1140, 2013.

CHIBA, M. K.; FILHO, O. G.; VIEIRA, S. R.. Variabilidade espacial e temporal de plantas daninhas em Latossolo Vermelho argiloso sob semeadura direta. Acta Scientiarum Agronomy, Maringá, v.32, n.4, p.735-742, 2010. DOI: https://doi.org/10.4025/actasciagron.v32i4.5445

CONCENÇO, G.; TOMAZI, M.; CORREIA, I. V. T.; SANTOS, S. A.; GALON, L.. Phytosociological surveys: Tools for weed science? Planta Daninha, Viçosa, v.31, n.2, p.469-482, 2013. DOI: $\underline{\text { https://doi.org/10.1590/S0100-83582013000200025 }}$

CORRÊA, M. J. P.; ALVES, G. L.; ROCHA, L. G. F.; SILVA, M. R. M.. Períodos de interferência de plantas daninhas na cultura do feijão caupi. Revista de Ciências Agroambientais, Alta Floresta, v.13, n.2, p.50-56, 2015.

COSTA, J. R.; MITJA, D.; LEAL FILHO, N.. Bancos de sementes do solo em pastagens na Amazônia Central. Pesquisa florestal brasileira, Colombo, v.33, n.74, p.115-125, 2013. DOI: https://doi.org/10.4336/2013.pfb.33.74.431

FERREIRA, E. A.; FERNANDEZ, A. G.; SOUZA, C. P.; FELIPE, M. A.; SANTOS, J. B.; SILVA, D. V.; GUIMARÃES, F. A. R.. Levantamento fitossociológico de plantas daninhas em pastagens degradadas do Médio Vale do Rio Doce, Minas
Gerais. Revista Ceres, Viçosa, v.61, n.4, p.502-510, 2014. DOI: https://doi.org/10.1590/0034-737X201461040008

FERREIRA, E. C. A.; MENDONÇA, C. G.; MONTANARI, R.; POSSAMA, A. C. S.; MENDONÇA, C. G.. Espacialização do banco de sementes de plantas daninhas sob diferentes manejos de cana-de-açúcar em Rio Brilhante, Mato Grosso do Sul. Bioscience Journal, Uberlândia, v.29, n.1, p.14581468, 2013.

FIGUEIREDO, P. H. A.; MIRANDA, C. C.; ARAUJO, F. M.; VALCARCEL, R.. Germinação ex-situ do banco de sementes do solo de capoeira em restauração florestal espontânea a partir do manejo do sombreamento. Scientia Forestalis, Piracicaba, v.42, n.101, p.69-80, 2014.

JAKELAITIS, A.; CARDOSO, I. S.; SOARES, M. P.. Banco de sementes de plantas daninhas em solos cultivados com culturas e pastagens. Global Science and Technology, Rio Verde, v.7, n.2, p.63-73, 2014. DOI: https://dx.doi.org/10.14688/1984-3801/gst.v7n2p63-73

LAU, A. V.; JARDIM, A. G. Composição e densidade do banco de sementes em uma floresta de várzea, llha do Combu, Belém/PA, Brasil. Biota Amazônia, Macapá, v.4, n.3, p.5-14, 2014. DOI: http://dx.doi.org/10.18561/21795746/biotaamazonia.v4n3p5-14

LEAL FILHO, N.; SENA, J. S.; SANTOS, G. R.. Variações espaçotemporais no estoque de sementes do solo na floresta amazônica. Acta Amazônica, Manaus, v.43, n.3, p.305-314, 2013. DOI: https://doi.org/10.1590/S0044$\underline{59672013000300006}$

LIMA, R. S.; SÃO JOSÉ, A. R.; SOARES, M. R. S.; MOREIRA, E. S.; ARAUJO NETO, A. C.; CARDOSO, A. D.; MORAIS, O. M.. Levantamento fitossociológico de plantas daninhas na cultura do feijão-caupi no município de Vitória da Conquista/BA. Magistra, Cruz das Almas, v.28, n.3/4, p.390402, 2016.

LIMA, S. F.; TIMOSSI, P. C.; ALMEIDA, D. P.; SILVA, U. R.. Fitossociologia de plantas daninhas em convivência com plantas de cobertura. Revista Caatinga, Mossoró, v.27, n.2, p.37-47, 2014.

LOPES, K. A. L.; SILVA, M. S.; COSTA, L. S.; SILVA, T. F.; COSTA, T. V.; ALMEIDA, E. I. B.; OLIVEIRA, I. R.; FREITAS, J. R. B.; SOUSA, W. S.; OLIVEIRA, L. B. T.. Spatial distribution of weed seed banks in the agricultural field and anthropized cerrado. Journal of Agricultural Studies, Las Vegas, v.8, n.2, p.480497, 2020. DOI: https://doi.org/10.5296/jas.v8i2.16031

LORENZI, H.. Plantas daninhas do Brasil: terrestre, aquáticas, parasitas e tóxicas. 4 ed. Nova Odessa: Instituto Plantarum, 2008.

LOUSADA, L. L.; ESTEVES, B. S.. Banco de Sementes de Plantas Daninhas em Áreas de Cana-de-açúcar no Norte Fluminense. Revista FINCA, v.4, n.1, p.49-58, 2017. DOI: http://dx.doi.org/10.37157/fimca.v4i1.9 
MACHADO, V. M.; SANTOS, J. B.; PEREIRA, I. M.; LARA, R. O.; CABRAL, C. M.; AMARAL, C. S.. Avaliação do banco de sementes de uma área em processo de recuperação em cerrado campestre. Planta Daninha, Viçosa, v.31, n.2, p.303312, 2013. DOI: https://doi.org/10.1590/S0100$\underline{83582013000200007}$

MESQUITA, M. L. R.; ANDRADE, L. A.; PEREIRA, W. E.. Banco de sementes do solo em áreas de cultivo de subsistência na floresta ombrófila aberta com babaçu (Orbygnia phalerata Mart.) no Maranhão. Revista Árvore, Viçosa, v.38, n.4, p.677-688, 2014. DOI: https://doi.org/10.1590/S0100$\underline{67622014000400011}$

MONQUERO, P. A.; AMARAL, L. R.; BINHA, D. P.; SILVA, P. V.; SILVA, A. C.; MARTINS, F. R. A.. Mapas de infestação de plantas daninhas em diferentes sistemas de colheita da cana-de-açúcar. Planta Daninha, Viçosa, v.26, n.1, p.47-55, 2008. DOI: https://doi.org/10.1590/S0100$\underline{83582008000100005}$

MUELLER-DOMBOIS, D.; ELLENBERG, H.. Aims and methods of vegetation ecology. New York: John Wiley e Sons, 1974.

NORSWORTHY, J. K.; WARD, S. M.; SHAW, D. R.; LLEWELLYN, R. S.; NICHOLS, R. L.; WEBSTER, T. M.; BRADLEY, K. W.; FRISVOLD, G.; POWLES, S. B.; BURGOS, N. R.; WITT, W. W.; BARRETT, M.. Reducing the risks of herbicide resistance: best management practices and recommendations. Weed Science, v.60, n.1, p.31-62, 2012. DOI: https://doi.org/10.1614/WS-D-11-00155.1
PASSOS, M. L. V.; ZAMBRZYCKI, G. C.; PEREIRA, R. S.. Balanço hídrico e classificação climática para uma determinada região de Chapadinha/MA. Revista Brasileira de Agricultura Irrigada, Fortaleza, v.10, n.4, p.758-766, 2016. DOI: https://dx.doi.org/10.7127/rbai.v10n400402

SCHAFFRATH, V. R.; TORMENA, C. A.; GONÇALVES, A. C. A.; OLIVEIRA JUNIOR, R. S.. Variabilidade espacial de plantas daninhas em dois sistemas de manejo de solos. Revista Brasileira Engenharia Agrícola e Ambiental, Campina Grande, v.11, n.1, p.53-60, 2007. DOI: https://doi.org/10.1590/S1415-43662007000100007

SHIRATSUCHI, L. S.; FONTES, J. R. A.; RESENDE, A. V.. Correlação da distribuição espacial do banco de sementes de plantas daninhas com a fertilidade dos solos. Planta Daninha, Viçosa, v.23, n.3, p.429-436, 2005. DOI: https://doi.org/10.1590/S0100-83582005000300006

SILVA, J.; CUNHA, J. L. X. L.; OLIVEIRA, F. S.; SILVA, R. G. S.; GOMES, C. B.; CARVALHO, A. P. V.; SILVA JUNIOR, A. B.; SILVA, C. A.. Composição do banco de sementes em diferentes profundidades de uma área cultivada com capim Aruana. Revista Agrarian, Dourados, v.11, n.40, p.140-149, 2018. DOI: https://doi.org/10.30612/agrarian.v11i40.5274

SILVA, M. R. M.; COSTA, E. A.; MARQUES, L. J. P.; CORRÊA, $M$. J. P.. Banco de sementes de plantas daninhas em áreas de cultivo de arroz de sequeiro na Pré-Amazônia Maranhense. Revista de Ciências Agrárias Amazônia, Belém, v.57, n.4, p.351-357, 2014. DOI: http://dx.doi.org/10.4322/rca.1297

A CBPC - Companhia Brasileira de Produção Científica (CNPJ: 11.221.422/0001-03) detém os direitos materiais desta publicação. Os direitos referem-se à publicação do trabalho em qualquer parte do mundo, incluindo os direitos às renovaç̃̃es, expansões e disseminações da contribuição, bem como outros direitos subsidiários. Todos os trabalhos publicados eletronicamente poderão posteriormente ser publicados em coletâneas impressas sob coordenação da Sustenere Publishing, da Companhia Brasileira de Produção Científica e seus parceiros autorizados. Os (as) autores (as) preservam os direitos autorais, mas não têm permissão para a publicação da contribuição em outro meio, impresso ou digital, em português ou em tradução. 